$1-2015$

\title{
Research Into Tennessee's Achievement School District: Autonomy, Incentives, and Guidance for Providers
}

Joshua L. Glazer

Diane Massell

Matthew Malone

Follow this and additional works at: https://repository.upenn.edu/cpre_policybriefs

Part of the Educational Assessment, Evaluation, and Research Commons

\section{Recommended Citation}

Glazer, Joshua L.; Massell, Diane; and Malone, Matthew. (2015). Research Into Tennessee's Achievement School District: Autonomy, Incentives, and Guidance for Providers. CPRE Policy Briefs.

Retrieved from https://repository.upenn.edu/cpre_policybriefs/6

View on the CPRE website.

This paper is posted at ScholarlyCommons. https://repository.upenn.edu/cpre_policybriefs/6

For more information, please contact repository@pobox.upenn.edu. 


\title{
Research Into Tennessee's Achievement School District: Autonomy, Incentives, and Guidance for Providers
}

\author{
Abstract \\ This is the first in a series of reports based on a multi-year research project on the Tennessee \\ Achievement School District (ASD). The purpose of these reports is to present independent analyses \\ based on evidence, as well as the experience and judgment of the research team. The current discussion \\ examines the ASD's theory of action, and considers how its system of accountability and guidance could \\ influence the nature of students' educational experiences. Particular attention is given to the diversity of \\ approaches among the organizations operating schools in the ASD, and the extent to which this could \\ lead to meaningful comparisons, discussion, and ultimately organizational learning. Our focus on \\ organizational learning is motivated by the belief that the capacity of ASD providers to learn and improve \\ is critical to the success of the overall enterprise.

\section{Disciplines} \\ Educational Assessment, Evaluation, and Research
}

\section{Comments}

View on the CPRE website. 


\section{RESEARCH INTO TENNESSEE'S ACHIEVEMENT SCHOOL DISTRICT: AUTONOMY, INCENTIVES, AND GUIDANCE FOR PROVIDERS}

Joshua L.Glazer - George Washington University, Diane Massell - Consortium for Policy Research in Education, Matthew Malone - George Washington University

This is the first in a series of reports based on a multi-year research project on the Tennessee Achievement School District (ASD). The purpose of these reports is to present independent analyses based on evidence, as well as the experience and judgment of the research team. The current discussion examines the ASD's theory of action, and considers how its system of accountability and guidance could influence the nature of students' educational experiences. Particular attention is given to the diversity of approaches among the organizations operating schools in the ASD, and the extent to which this could lead to meaningful comparisons, discussion, and ultimately organizational learning. Our focus on organizational learning is motivated by the belief that the capacity of ASD providers to learn and improve is critical to the success of the overall enterprise.

The analysis is informed by evidence collected between September 2013 and November 2014. During that time, researchers conducted two sets of interviews with the leaders of the ASD, and with the leaders of all the operators running schools in the 2013-14 school year. The interviews were designed to pursue three broad goals. The first was to understand the ASD's strategy for improving educational outcomes, and the key policies formed in support of that strategy. The second was to understand the educational designs adopted by each of the operators (most of whom are Charter Management Organizations). The third was to explore issues, including some outside the boundaries of the ASD, that influence-both positively and negatively - the work of the ASD and its operators. Subsequent reports will address these topics more fully.

The report is not an evaluation of the ASD or the school operators. Rather, it highlights practical issues intended to contribute to the ASD's strategic efforts to secure an array of viable, high quality schooling choices for its students. Overall, our findings suggest that the ASD is driven by extraordinary determination and commitment among ASD leaders and the organizations operating schools. We encountered many individuals and organizations unequivocally dedicated to the practical and ideological mission of the ASD. At the same time, promising reforms have arisen in the past only to disappear within a few years, and for those that endure, reversing deeply entrenched patterns of failure is a monumental challenge that has rarely been accomplished on a large scale. With this in mind, our intent is to highlight topics and dilemmas that can strengthen the ASD's longterm sustainability and effectiveness, and that can offer guidance to similar efforts underway in other places.

Finally, on behalf of the entire research team we express thanks to the members of the ASD and the staff of the six charter management organizations for their cooperation and candor.

Joshua Glazer and Diane Massell

November 2014

Direct all correspondence to: Joshua Glazer, Graduate School of Education and Human Development, George Washington University, 2134 G Street, NW. Washington DC. 20052. jglazer@gwu.edu.The authors gratefully acknowledge funding received from the Spencer Foundation and Walton Family Foundation in support of this work. 


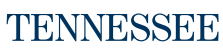

\section{CONSORTIUM \\ on Research, Evaluation \& Development}

\section{EXECUTIVE SUMMARY}

The Achievement School District (ASD) was created in 2011 to assume authority over a segment of the lowest performing schools in Tennessee. As a state-run entity, the ASD represents an unusual system of governance in US education. It has the legal responsibilities of a district, the authority of an authorizer, and an enrollment policy that allows choice to a segment of students eligible under state law to participate. It has set an extraordinarily ambitious goal of moving schools into the top quartile of performance on the state assessment, but relies on external providers to do the work of designing and implementing plans for curriculum, instruction, and leadership.

To meet its ambitious goals, the ASD has adopted explicit policies or practices that include a commitment to allowing providers the autonomy to innovate and adapt to the needs of students; to outcomes coupled with high stakes accountability; and to creating a collegial environment to support the improvement and learning of each provider. In this brief, we describe these three key pillars of their management philosophy and consider the short- and potential long-term effects of their efforts to enable provider diversity and organizational learning.

Our initial results reveal that the ASD's emphasis on autonomy and related agnosticism about particular instructional designs has resulted in a diverse array of schooling choices, with designs that reflect fundamental differences in providers' approach to teaching and learning. In some cases, providers combine a more teacher-centered approach to classroom instruction with a heavy focus on student behavior and discipline, while other providers use instructional methods that promote argumentation and debate, student-led solutions, group work, and problem-solving skills. These emphases suggest markedly variant educational philosophies, and very different ideas about how students best learn and grow. They have the potential to create very different experiences for students.

While the ASD has been successful in including a variety of designs in its portfolio in the short-term, questions remain about whether divergent approaches will flourish and stabilize over time. As in much of the nation, the decision whether to align new state assessments with the Common Core State Standards is again under debate in Tennessee. If tightly aligned, state tests may privilege models that effectively orient towards higher order thinking and problem solving skills. If Tennessee continues with a version of its current assessment, these types of instructional strategies will be at a disadvantage if they do not produce immediate results, regardless of providers' learning philosophies. Other incentives, such as parental preference and choice seem unlikely to match the importance of assessment results. 


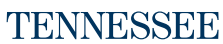

\section{C@NSORTIUM}

on Research, Evaluation \& Development

In addition to autonomy and accountability, the ASD also invests considerable resources to foster learning among its provider organizations. They believe that all provider organizations-including the most seasoned ones with proven track records - have a great deal to learn, and that establishing an environment that contributes to continuous improvement is important to success. In addition to expectations that providers will learn about effective practices from assessment outcomes, the ASD uses key learning processes, such as School Practice Reviews (SPRs) and regular meetings of operators, to promote collegial discourse and exchange. While the ASD seeks to refrain from intervening on schooling processes, they hope that these initiatives will yield information and advice that the providers will then take to improve their work.

Early evidence suggests that while operators are eager to improve, designing potent learning opportunities is a formidable challenge. It is difficult for providers to make valid inferences from annual test scores about which aspects of a particular model are driving performance. Indeed, hypotheses abound within the ASD (many of them conflicting) as to what lessons should be taken from assessment outcomes. Secondly, while the SPRs do shine a light on many critical dimensions of teaching and learning, preliminary data suggest that these opportunities have not yielded sustained and in-depth analysis of practice or significant changes in the work. The ASD is continuing to revise the design of the SPR, and finding ways to increase the quality and duration
Early evidence suggests that while operators are eager to improve, designing potent learning opportunities is a formidable challenge. It is difficult for providers to make valid inferences from annual test scores about which aspects of a particular model are driving performance. of discussion about practice could lead to a more substantive learning experience for providers.

The ASD's commitment to organizational learning is compelling due to the enormity of the educational challenge that the ASD and its partner organizations confront. Translating that commitment into sustained and productive discourse about the work of improving teaching and learning may come with time if the conversations across providers hone in on the meaningful questions about the design of teaching and leadership practices. The ASD is still in its infancy, and the time, energy, and wherewithal needed to support this type of learning community may emerge with time.

${ }^{1}$ Priority schools, which rank in the bottom $5 \%$ of performance on combined state English language arts and mathematics tests, or achieve less than a $60 \%$ graduation rate, are eligible to be removed from their local education agency and placed into the ASD. 


\section{THE ASD THEORY OF ACTION: AUTONOMY, ACCOUNTABILITY AND ORGANIZATIONAL LEARNING}

In 2011, Tennessee created the Achievement School

District (ASD), a state-run entity to oversee and improve the state's most persistently low-achieving "priority" Title I schools. "When the ASD opened its doors in 2012-13, six of these schools came under its jurisdiction; by 2013-14, that figure had risen to seventeen and is projected to grow to 30 for the 2015-16 school year.

The ASD represents an unusual system of governance in US education. It has the legal responsibilities of a district, the authority of an charter authorizer, and an enrollment policy that allows choice to a segment of students eligible under state law to participate. It has set extraordinarily ambitious goals for the performance of schools with a long history of failure, pledging to move schools performing in the bottom $5 \%$ of the state into the top quartile within five years. It relies on external providers-mostly charter management organizations - to do the work of designing and implementing plans for curriculum, instruction, and leadership. In this context, the ASD does not take on many of the functions of a traditional district, and seeks to maintain a lean organizational structure with only a few dozen staff members. Its overarching management philosophy and ensuing strategies center around three key pillars: autonomy for providers to create a robust set of choices to meet the diverse needs of students and families; a strong commitment to outcomes coupled with high stakes accountability incentives; and the development of tools for self-reflection and a collegial environment to support the improvement and learning of each provider.

Despite this non-traditional structure and approach to governance, the ASD retains many of the legal responsibilities of a regular school district, including compliance with rules and regulations governing federal and state programs (e.g., the service of special needs students or English language learners). Likewise, the ASD must assure that its charter networks open their doors to all students within "attendance area boundaries." These zones thus provide operators with a ready pool of studentsan advantage that traditional new charter schools do not enjoy. But these state policies also impose particular constraints and complexities. Students may opt to attend a different priority school outside their attendance area. By the same token, charter providers can only recruit students from outside their neighborhoods if the students are zoned for a priority school. Thus in the end, the advantage of not having to compete with another neighborhood school is tempered by a limited ability to fill vacant seats.

\section{Autonomy to Build Diverse Choices for Students}

Unlike districts that establish policies regarding textbooks, curriculum, professional development, and hiring practices, the ASD values autonomy and the variability in schooling practices that may emerge as a result. Indeed, a key idea behind the overall concept of "portfolio management," ${ }^{2}$ of which the ASD is one 


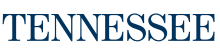

\section{CONSORTIUM \\ on Research, Evaluation \& Development}

version, is that a broad

variety of educational

approaches will enable

district administrators

(and perhaps providers)

to develop a better

understanding of what is

and what is not working,

and to provide diverse

options for students'

diverse needs. As one

ASD staffer put it: "I think

that if we are going to

serve all the students that

are zoned to go to us, we

need to have a lot more

options. ...We should

be actively seeking out

a variety of types of settings so that all kids can feel

successful and be interested in school."

\section{Outcomes-Based Theory Of Management}

And Accountability

The ASD embraces a theory of management and accountability that is at once outcomes-oriented and "devoutly agnostic" about the educational strategies that networks use to attain results. The underlying idea is that minimizing bureaucratic constraints on operators and school professionals while holding them accountable for student performance will spur innovation and creativity while ensuring that the needs of students are the top priority. This is not a new idea in American education, but the fact that the ASD is a state-sanctioned, local education agency (LEA), and not just a traditional authorizer, gives this a particular character in which regulatory and market mechanisms are combined in an unusual manner.

The emphasis on autonomy and the aversion to bureaucracy represent a philosophy that is deeply felt by ASD managers, many of whom themselves are products of the charter movement where such ideas are sacrosanct. Far from an abstract set of beliefs, this philosophy guides day-to-day decisions in the ASD. Indeed, ASD superintendent Chris Barbic emphasized that his and other ASD staffers' personal views on schooling should not inform official ASD policy; rather, they should focus exclusively on the bottom linestudent achievement results.

While I may have personal views, ... I think that my job as ASD sup' is to make sure that at the end of the day we're looking at the results, and if it's all direct instruction and the school's getting great results, fine. If it's all project-based learning, and they're getting results, that's fine too. If it's textbooks, I mean I don't necessarily agree with that, but if there's an organization that knows how to do that in a way that's engaging for kids, they can get results, then we're not going to judge based on that. 


\section{Trasere}

\section{NSORTIUM \\ on Research, Evaluation \& Development}

While past research has noted that districts are typically characterized by considerable diversity of beliefs and ideas, the ASD is remarkable for the consistency with which its core staff subscribes to its underlying theory of action. Repeatedly, we heard unwavering commitment to allowing providers freedom to employ their own approach, as long as they improve student outcomes. Staff members passionately articulate their efforts to avoid becoming a traditional, centralized district bureaucracy.

The ASD's aversion to intervening on educational process does not mean that it has adopted a lax style of management. It has tremendous authority over providers through its control over school authorization, expansion, and closure. It aims to exercise its power primarily by removing providers who do not produce results and expanding only those that do. The ASD has both interim targets as well as its five-year goal for schools to perform in the top $25 \%$ of the state. For the interim accountability, it created its own School Performance Framework that sets annual achievement and graduation-rate targets across subject areas and subgroup populations. These metrics and additional indicators, such as financial management, inform decisions as to whether operators will be allowed to continue their work, or continue planned expansions.

In sum, expected outcomes are ambitious, monitored, and firm, but the means to achieve them are largely left to the discretion of providers.

\section{Learning community for charter providers.}

While the ASD does not directly determine the content of providers' curricular or instructional programs, they do seek to ensure that certain educational processes and standards are maintained. This is driven, in part, by their legal obligation to ensure compliance to federal/state rules and regulations. Another reason for engaging with providers' educational program, however, is their recognition that attaining high student learning goals will require considerable and sustained organizational learning. This is particularly germane for the new (and often local) charter organizations that the ASD has recruited. These emerging organizations are important in that they enable the ASD to increase the number of schools under its purview, and to include local educators and reformers in its network of providers. Yet absent the experience and robust organization infrastructure that national CMOs rely on, these organizations are more in need of intensive assistances and supports to grow and stabilize.

ASD managers believe that all providers-including the most seasoned ones with proven track recordshave a great deal to learn, and that establishing an environment that contributes to continuous improvement is important to the ASD's long-term success. It is not difficult to understand the underlying reasoning. ASD leaders believe that providers' capacity to learn and adapt is critical to the ASD's overall success.

I think one of the success makers here is that given the wildly divergent and high needs of some of our students - (providers) need to be able to leverage their resources across networks, across CMOs, to meet students' needs. Because they are serving students with such diverse needs, without the ability to easily exit the students for non-compliance or for not fitting into the program, they will need to be flexible and/or leverage their collaborative network of other operators in a way that they don't usually have to do in other districts." 


\section{Trasere}

\section{NSORTIUM \\ on Research, Evaluation \& Development}

The ASD has taken several measures to create an environment that supports this type of learning. Most prominent among these are the "School Practice Reviews" (SPR), which are designed to offer feedback to providers on the state of instruction, leadership, and other key processes from a team of visitors who observes instruction and interviews school leaders, teachers, students, and parents. According to the literature from SchoolWorks, the organization contracted to design and oversee the process, the purpose of the SPR is to:

Provide school and ASD leadership the opportunity to engage in, and receive, qualitative feedback tied to indicators for school improvement. There are also opportunities for school leaders to engage in reflection, a starting point for mid-year collaborative planning for school teams, and an opportunity for the ASD leadership to identify areas in which it can better serve and support schools (p.1). ${ }^{3}$

The ASD frequently includes members of other charters on the review team in order to help them gain insight into how different organizations are tackling similar issues. Feedback is given to leaders in the targeted school, which is then followed by a formal report that is delivered approximately two weeks later. Importantly, and in keeping with its commitment to autonomy, providers are not obligated to act on the advice. Nevertheless, as one ASD leader put it, the hope is that the SPRs will lead to incremental improvements:

They get very actionable feedback and so if we can say these things - from $X$ number of schools we see that these things tend to predict great outcomes and this is how you are looking on these measures, you can choose to make corrections or not but you're going to be held accountable for your outcomes at the end of the year. The assumption is with some really strong information of that sort that operators will weigh off on those indicators would do some mid-course - mid-year corrections instead of end-ofyear corrections based on that information.

In the remainder of this brief, we take a first step toward looking at how the three key pillars of the ASD's management philosophy played out in the 2013-14 year, the second full year of provider operations. We consider whether the ASD's approach enabled diverse schooling choices, and how outcomes accountability and other incentives may influence that variety in the long term. We also consider the early evidence about the ASD's effort to establish a learning environment that supports reflection and improvement. The analysis is organized around four questions:

1. Has the ASD regime enabled a diverse array of schooling options to emerge for parents and students?

2. What are the key incentives for providers, and how are they likely to influence their decision making?

3. How is the focus on assessed outcomes guiding learning for providers and the ASD?

4. Is the ASD developing a learning community among providers, and building a foundation for improving school designs? 


\section{Trasere}

\section{CONSORTIUM \\ on Research, Evaluation \& DeVelopment}

\section{EDUCATIONAL DIVERSITY, GUIDANCE AND LEARNING IN THE ASD}

(1) Has the ASD regime enabled a diverse array of schooling options to emerge for parents and students?

The ASD has attracted and authorized a broad range of charter management organizations in its first few years of operations. These providers bring distinct educational philosophies to the ASD, with different conceptions of what counts as a rigorous approach to content, and different types of learning opportunities. The ASD has diligently strived to maintain neutrality and operator autonomy to maintain and legitimize these different paths.

The charters in place have different ideas about effective teaching and about the kind of student culture that is necessary to support a learning environment. For example, several providers offer an instructional approach that centers around direct instruction and students' independent practice. In this instructional system, the "I do, we do, you do" technique-a common procedure for several providers-- is viewed as the most effective way to expose students to correct information and to allow sufficient time for students to practice and obtain mastery. One provider explained the rationale behind this technique:

If you compared independent practice say to one student coming up to the board and working the problem, you know, the first scenario you got 25 kids all working the problem and the second scenario you got 24 kids watching one. So, the more wiggly (kids become). The more kids get practice time, the more they're going to grasp and master the concept. So we're more likely to have everybody working rather than one or two working. The second thing I would say is that the teacher is always the smartest person in the room, and so we're less likely to (have students) help your partner than (to say) this is the proper way to do it, and it's delivered by a teacher saying this is step one, step two, step three.

This provider also places a heavy emphasis on guiding student behavior - "culture," in their terms - which they view as necessary to inculcate discipline and minimize disruptions to learning time. A similar model seeks to maximize student engagement and instructional time by specifying in extraordinary detail how students move through the hallway, raise their hands, and sit at their desks.

So in each classroom you should see scholars "at slant" is what we call it, when they're sitting up straight, looking at the teacher, paying attention. You should see scholars using what we call a [name] High Fives, so if they have an answer to a question, or they have a question, there's a certain finger that they hold up - or if they have to use the restroom, it's a three or if they need materials it's a two, so there isn't that calling out all the time which can cause disruption in the class.

These providers believe that by enforcing this system they directly address the gaps in students' foundational academic skills or behaviors that have prevented them from learning and achieving in school.

In contrast, other providers have adopted approaches that promote more student-to-student discourse, project-based learning, group work, and more openended problem solving opportunities. These designs 


\section{craste}

\section{NSORTIUM \\ on Research, Evaluation \& Development}

define the teacher as facilitator and less as the "smartest person in the room." Note the difference in the way one of these providers described their underlying ideas about teaching and learning:

We believe in the importance of students talking to students during the classroom and using evidence to defend their ideas. That's what we define as 'rigor'. Rigorous teaching is when students are able to do that. And so we provide students with the opportunities through our instructional guidelines to do that during the day, whether it's studentlead solutions in math or it's working in that group together, and reading and they're doing graphic organizer, or in Shared Inquiry on Thursdays, it's a whole class discussion and they have to refer to the texts.

Interestingly, this same provider discussed her network's previous allegiance to the "I do, we do, you do" model and their deliberate move away from it:

We historically have really loved this "I do, we do, you do" model. But we can't continue to do that if we want our kids to be able to think and reason mathematically. We .... have to let go a little bit. We can't say to kids, okay, this is how you do a division problem. This is the one way to do a division problem. Copy the steps that I did to, exactly. And now from now on, every time you do division, that's the way you're going to do your problem.
(2) What are the key incentives for providers, and how might they influence decision making?

These variations in educational philosophy point to the ASD's success in attracting an eclectic population of providers, and providing them with the autonomy to put their varied designs into place. At the same time, questions remain about whether these incentives are enough to enable these variations to flourish and stabilize in the ASD environment in the long term.

Under the intended theory of action, parental choice should be a strong driver in the marketplace, as
These variations in educational philosophy point to the ASD's success in attracting an eclectic population of providers, and providing them with the autonomy to put their varied designs into place. At the same time, questions remain about whether these incentives are enough to enable these variations to flourish and stabilize in the ASD environment in the long term. should results on challenging achievement outcomes embedded in the accountability system. Indeed, it is possible that parent selection will contribute to a diverse population of providers that reflects the variable needs of students, particularly if the foundations of informed and effective choice become wellestablished, such as accurate information, and ready access to transportation to the selected school.

However, even if parent choice emerges as a factor, the content of state assessments and the design of the accountability programs are likely to be (more) powerful incentives for what charter providers ultimately do with their designs for curriculum and instruction. Similarly, although School Practice Reviews, surveys, interim assessments, and other process-oriented indicators are meant to encourage 


\section{masuste}

\section{NSORTIUM \\ on Research, Evaluation \& Development}

self-reflection and positive change, these indicators do not inform the high stakes decisions that determine the expansion or closure of CMOs, or factor into the metrics that are reported to the public about the ASD's overall performance.

Several operators and ASD managers claim that Tennessee's existing assessments-the Tennessee Comprehensive Assessment Program (TCAP) - offer little incentive for providers to orient their designs toward the development of higher order thinking or advanced problem-solving skills. For example, when asked about the difference between TCAP and Common Core standards, one ASD staffer put it this way: "The Common Core is so rigorous and deep and I think TCAP, historically, is so shallow and broad." Another ASD staffer offered a similarly tepid assessment of TCAP: "Does it show that our kids are getting smarter or that they are better equipped to perform outside of the schools or outside of this test? No. ... My hope is that Common Core will alleviate some of that distinction."

Tennessee officially adopted the CCSS in 2012-13, and the current timetable calls for CCSS-aligned assessments to be introduced in 2015-16. At the time of this writing, however, there is a great deal of uncertainty whether these plans will be carried out according to this schedule or if at all. Nonetheless, the anticipation of Common Core aligned assessment did begin to spur some rethinking on the part of providers we interviewed in 2013 , with several looking for ways to incorporate more student-centered and inquiryoriented pedagogies into their practice. Whether that trajectory continues likely hinges to a large part on the future assessments that the state adopts. Indeed, while all schools are under pressure to perform, the ASD's demanding, ambitious target of moving enormously under-performing schools into the top $25 \%$

One way or another, the state's decision to maintain its current standards and assessments or introduce new ones is likely to have significant implications for the ASD, and considerable impact on providers' diversity and survival.

of state performance greatly amplifies the importance of tailoring one's educational design to the specific measures and constructs included in the test. Barbic claims that the centrality of the state assessment in the ASD's overall approach is "in its DNA." Other staff members were somewhat less sanguine, such as one who acknowledged that "our goal, the goal of our education system ... is just literally how well can you get your kids to perform on this one test once a year."

One way or another, the state's decision to maintain its current standards and assessments or introduce new ones is likely to have significant implications for the ASD, and considerable impact on providers' diversity and survival. Common Core-type assessments may press providers to make significant alterations to their designs in ways that depart from their central ideas about effective teaching and learning, including components that are appealing to parents. The decision will also go a long way toward determining the incentives and guidance that inform the providers' educational strategies and ultimately students' learning 


\section{masuste}

\section{NSORTIUM \\ on Research, Evaluation \& Development}

experiences. This leads to our next question as to what inferences can be drawn from assessment results about providers' models.

(3) What lessons are providers and the ASD learning from the state assessments?

While the ASD is not seeking mandate particular practices that are predictive of outcomes, assessed student achievement is undoubtedly the lingua franca of effectiveness. As such, the lessons that providers and ASD officials draw from test results are of considerable importance.

To be sure, assessments can provide a snapshot of student performance useful to policymakers, school leaders, and teachers. Moreover, in an environment where outcomes dominate public discourse on education, high profile initiatives like the ASD must perform well to maintain legitimacy. Nonetheless, even in ideal circumstances, interpreting and drawing inferences from assessment scores about educational programs and practices is not straightforward, and implications can be easily misconstrued. For example, slight changes in student demographics can alter scores considerably, and "percent above cut scores" can exaggerate perceptions of progress while masking legitimate learning gains that take place within bands of "below proficient," "proficient," or "above proficient.

Another challenge is that the multi-dimensional nature of these school turnaround models makes it difficult for providers to identify which components of their approach are responsible for performance (or lack thereof). The more that providers adopt a comprehensive strategy that addresses factors such as instructional practice, student motivation, parental involvement, attendance, leadership, and class size, the harder it is to isolate the key drivers on student learning. In such circumstances, drawing solid conclusions about the efficacy of a model on student achievement requires a large sample and a careful evaluation design that is beyond the capacity of most providers and even districts. Indeed, the difficulty of drawing firm conclusions about the relationship between turnaround strategies and student outcomes seems to have contributed to a wide (and often conflicting) array of hypotheses within the ASD as to what lessons they should learn from the assessment results. For example:

- A leader in one $\mathrm{CMO}$ questioned whether their strong results were a function of their instructional model or simply because they provided students with experience using computers which, in turn, increased students' comfort level with computerbased assessments.

- The leaders of another CMO argued that their disappointing results stemmed from the fact that their model was more aligned to the CCSS than the Tennessee Comprehensive Assessment Program (TCAP), whereas a leader in another CMO claimed that their focus on CCSS-like instruction contributed to strong results on TCAP.

- ASD leaders argued that "phase-in" models that proceed one grade at a time enables CMOs to slowly adjust and refine their model, while some CMO leaders doubted whether success in a couple grades would lead to success at the level of an entire school. 


\section{Trasere}

\section{C@NSORTIUM \\ on Research, Evaluation \& Development}

- Some providers argued that because scores are starting so low even a minimal level of structure will create a bump in results, whereas others believe that because students' academic baseline is so low it will take a few years to realize meaningful improvement.

The ambiguity of deciphering the connection between assessment results and educational strategies is felt by the ASD as well. One member of the ASD stated this bluntly: "I think that we feel very confident that the things that we are measuring are the right things to measure in terms of outcomes. In terms of indicators, we have no idea. I mean we are still trying to figure it out."

One implication is that assessment results are of limited value in supporting organizational learning for providers and the ASD, itself.

A strong or weak performance does not lead to a clear understanding of what aspects of a provider's approach is working, what needs refinement, and what needs more substantial rethinking. Indeed, models that represent similar approaches to instruction and student learning did both poorly and well on the recent TCAP. Clearly, caution should be exercised in drawing conclusions about the efficacy of particular strategies from single-year results.
State assessments also provide ASD managers with a limited understanding of the quality of students' educational experience. ASD leaders state that their over-arching goal is to produce students that are well prepared for future educational and career success. A heavy focus on tests, however, can mask practices that are harmful to students but elevate scores, as well as overlook practices that are beneficial but do not have direct correlation to results. Indeed, more than a decade since the federal No Child Left Behind legislation created a high-stakes system of accountability, researchers and educators have repeatedly warned that scores can be inflated in multiple ways-e.g., teaching to the test, narrowing the curriculum, diverting resources to students just below proficiency-that do not reflect meaningful student learning and that do little to prepare students for more demanding academic work. ${ }^{4}$

We have not uncovered any evidence that ASD providers have engaged in this type of behavior, but they are acutely aware that such practices exist. One provider noted:

We all know how to play the game, and we chose not to play that game, because we don't think it's right. But you could sit there and target kids who are on the cusp and bubble students and do all that kind of stuff. .... We could have used all of our

${ }^{4}$ See Koretz and Jennings (2010) for a thorough discussion about the use and misuse of assessment results. 
$R T I$ (Response to Intervention) resources to target the bubble kids. But we didn't. And when I sat in the SIG (School Improvement Grant) conference with the principals who got the SIG grant and they said that's what they were doing, I was just like, I couldn't sleep at night if I did that.

Even if ASD providers eschew some of the most egregious forms of test preparation, it is still the case

In some ways, the ASD has many of the ingredients that could lead to strong collegial ties across organizations. All providers are charged with the same task, work with the same resources, and cope with similar challenges that stem from a unique environment.

that variation in providers' designs has ramifications for students' educational experience beyond what current tests, indeed any tests, can measure. Analysis of ASD students' educational experience and the type of learning opportunities afforded them would require a more fine-grained examination of the design and implementation of providers' models than analysis of assessment outcomes can support. The next question, then, is even more crucial for learning and growth in the ASD environment:

(4) Is the ASD developing a learning community among providers, and building a foundation for improving school turnaround models?

The ASD's current strategy assumes that collecting and sharing data about programs, with opportunities for self-reflection, as well as opportunities to meet and discuss practice with others will yield knowledge that can drive steady improvement of providers' turnaround strategies. As noted above, the ASD brings in an external partner, SchoolWorks, to organize School Practice Reviews (SPR), and in addition collects other information such as school climate surveys. It has also created multiple opportunities for dialogue intended to promote a collegial exchange of ideas. Furthermore, ASD leaders hope that the geographic proximity of the providers will lead to an informal network where providers share ideas and learn from one another. Barbic expressed this part of the strategy: "The fact is right now people are hopping on planes and going and visiting each other's schools today. If instead of hopping on a plane, you now drive down the street it just facilitates the sharing even more."

Currently, the most significant of these initiatives is the SPRs, and the ASD has invested considerable financial and human resources to conduct these events. These include many person hours from their own staff, but also from the charter providers who elect to participate on the team of observers. Perhaps the most extensive opportunity costs flow from the "host" providers who are the target of the review. These school leaders, teachers and parents arrange and often participate in classroom observations, interviews, and focus groups.

In some ways, the ASD has many of the ingredients that could lead to strong collegial ties across organizations. All providers are charged with the same task, work with the same resources, and cope with similar challenges that stem from a unique environment. In short, they share many of the same experiences. Moreover, the SPR protocol does direct 


\section{Thasuste}

\section{C@NSORTIUM \\ on Research, Evaluation \& Development}

attention to several fundamental issues that could focus productive discussions about their educational program strategies. For example, questions such as the extent to which teachers "develop higher order thinking skills," "students engage with teachers and peers in extended, content-focused discussions," and "teachers provide opportunities for student group work and peer tutoring" could surface critical distinctions about the models that, in turn, could lead to substantively important dialogue among providers. The fact that the process involves observations of classroom instruction and conversations with teachers could further ground discourse in the practical challenges of school improvement. Were such conversations to become on-going, the ASD could evolve into a repository for the development

of practical knowledge into the work of school turnaround.

Thus far, however, our evidence suggests that SPRs and other ASD initiatives have not leveraged significant change in providers' strategies, or led to sustained collegial discourse on key educational issues. On the one hand, representatives from all providers reported that they found the SPRs and interactions with different providers to be "useful," "informative," and, on occasion, "eye-opening." This is particularly true for those who participate on the review teams in other buildings where intense debates about observed practice frequently occur. On the other hand, the target of the work - the provider under review - has a very limited opportunity to engage in such conversation. Rather, the school and network leaders receive a brief presentation of findings at the end of the day that is followed by a written report two weeks later. One provider noted that the current format does not cultivate the school's "ownership" of the process or the results.

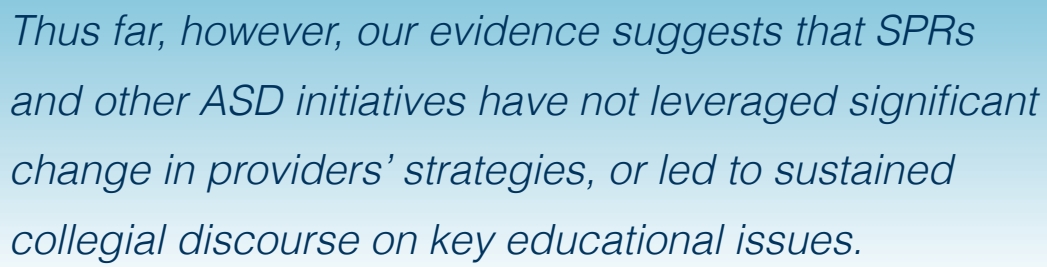

Thus far, however, our evidence suggests that SPRs and other ASD initiatives have not leveraged significant change in providers' strategies, or led to sustained collegial discourse on key educational issues.

The way the debrief was structured didn't really allow the school team to make a lot of meaning or do any further celebrating. I think the debrief could've been structured so that the school team was given a chance to read some of the evidence and talk in the small group about what some of the strengths and opportunities are. Or maybe the school team could have a chance to say "here's what we predicted in these categories, so that the school team has more ownership of the different domains and the observation tool. And they're truly interacting with the results and owning what the team may have seen. But reading the slides and saying do you have any questions, you're never going to get adults to actively participate that way.

Providers' minimal involvement in debates about the schools in their network may help to explain why no one perceived that the process spurred in-depth thinking about their approach or any serious changes to their model. For many, the SPR seemed to confirm what they knew or led to some tinkering around the edges. The following remark was typical: 
It's hard to identify specific areas, but I would say in almost every gathering we come away either confirming something that we're doing as being right or finding a nuance that can help us do something better.

Designing SPRs and other collegial opportunities among providers that lead to honest discussion and reflection is not a simple undertaking. Relationships of trust need to be cultivated among organizations operating in competitive environment. The importance of trust was underscored by at least one provider who commented that these reviews gave competitors too much information about their designs and hardwon lessons learned. Digging into fundamental issues (and not just tactical approaches) requires sustained discourse, which, in turn, will require time and patience. As once-a-year events, the SPRs do not provide formal opportunities for continued conversation.

Thus far, it is uncertain whether these and other ASD initiatives to build collegial exchange will lead to a high level of organizational discourse and learning. The current extent of variation among providers' approaches suggests that additional effort will be required to find common ground on which to base discussion. Given the human and financial resources necessary to sustain the effort, providers are likely to calibrate their investment to what they perceive as the potential benefits. Absent strong incentives, providers may opt to go through the motions without seriously engaging the process.

This does not mean that the SPRs or other collaborations cannot contribute to meaningful, ongoing conversations that leverage the experience, knowledge, and commitment that the ASD has assembled. The ASD is still in its infancy, and the time, energy, and wherewithal needed to support this type of learning community may emerge with time. The ASD staff is currently engaged in a critical review of the process, and is considering ways to enhance its usefulness.

In closing, we remind the readers that this is only a very partial rendering of what we have learned over the past year of work with the ASD - and only a very partial portrayal of the important strides that the ASD has made as a young organization innovating in a very difficult environment. Our purpose is to help them reflect in new ways on some of the problems and issues that they well recognize. The managerial

The ASD is still in its infancy, and the time, energy, and wherewithal needed to support this type of learning community may emerge with time.

tensions we describe stem from their heroic effort to foster an environment where autonomy, diversity, strong outcome accountability and organizational learning contribute to dramatic improvements in student learning in schools with a long history of failure and poor performance. We hope that unearthing these tensions and holding up a mirror will help the ASD and others seeking to embark on similar tasks to accomplish their goals. We thank the ASD and its partner organizations for their openness in sharing their work and their challenges with us. 
on Research, Evaluation \& Development

\section{References}

Hill, Paul Thomas, Christine Campbell, and Betheny Gross. (2013). Strife and progress: Portfolio strategies for managing urban schools. Brookings Institution Press.

National Governors Association. (2008). Benchmarking for Success

Porter, A., McMaken, J., Hwang, J., \& Yang, R. (2011). Assessing the Common Core Standards: Opportunities for Improving Measures of Instruction. Educational Researcher, 40(4), 186-188.

Koretz, D., Jennings, J.L. (2010). The Misunderstanding and Use of Data from Educational Tests. Downloaded from the Spencer Foundation website. www.spencer.org/resources/content/3/3/8/.../Koretz--Jennings-paper.pdf 